\title{
Research on Integration of Production and Education with Innovation and Entrepreneurship Education Mode under the Background of Emerging Engineering Education
}

\author{
Qian Wang 1, a, Xiaoyu Wang 2,b* and Xiaoguang Yang ${ }^{3, c}$ \\ 1,2,3 Dalian Neusoft Institute of Information, Dalian, Liaoning, China \\ a wangqian@neusoft.edu.cn, b wangxiaoyu@neusoft.edu.cn, c yangxiaoguang@neusoft.edu.cn
}

Keywords: Emerging engineering education; Integration of production and education; Innovation and entrepreneurship education

\begin{abstract}
Under the background of emerging engineering education, this paper studies the reform of teaching mode, curriculum evaluation and evaluation methods, and puts forward a diversified application-oriented personnel training mode with the combination of production and learning as the core to meet the needs of society. We should re-examine the training target of professionals according to market demand.
\end{abstract}

\section{Introduction}

General secretary Xi Jinping put forward in the nineteen major reports of the party:"Deepening integration of production and education and cooperation between schools and enterprises". He proposed giving priority to the development of education in the new situation, and promoting structural reform of supply side of human resources[1]. We must take the initiative to deal with a series of national strategies, including a new round of technological revolution and industrial transformation, support services innovation driven development and "Made in China 2025", etc[2]. Since February 2017, the Ministry of education has promoted the construction of new engineering disciplines, formed the "Fudan consensus", "Heaven action" and "Beijing guide" successively. The Ministry of Education issued the notice of "Notice on new engineering research and Practice" and "Notice on promoting new engineering research and practice project", in order to help the construction of a power of Higher Education.

Engineering management attaches great importance to integration of production and education, provides real scene for students for improving their professional skills, through the establishment of off campus training bases with many enterprises[3]. In the process of school enterprise cooperation, engineering management with the enterprises to jointly set up multiple training bases and meet the needs of professional teaching laboratory. At the same time, based on the needs of post competency, we combined the relevant enterprises by sector, joint research program, developed a set of needs and social development of the combination of curriculum system. A fair, impartial and open evaluation mechanism has been established by schools and enterprises to ensure the efficiency and enthusiasm of students in schools and training bases[4]. The innovation and entrepreneurship education mode of integration of production and education is shown in Fig.1. 


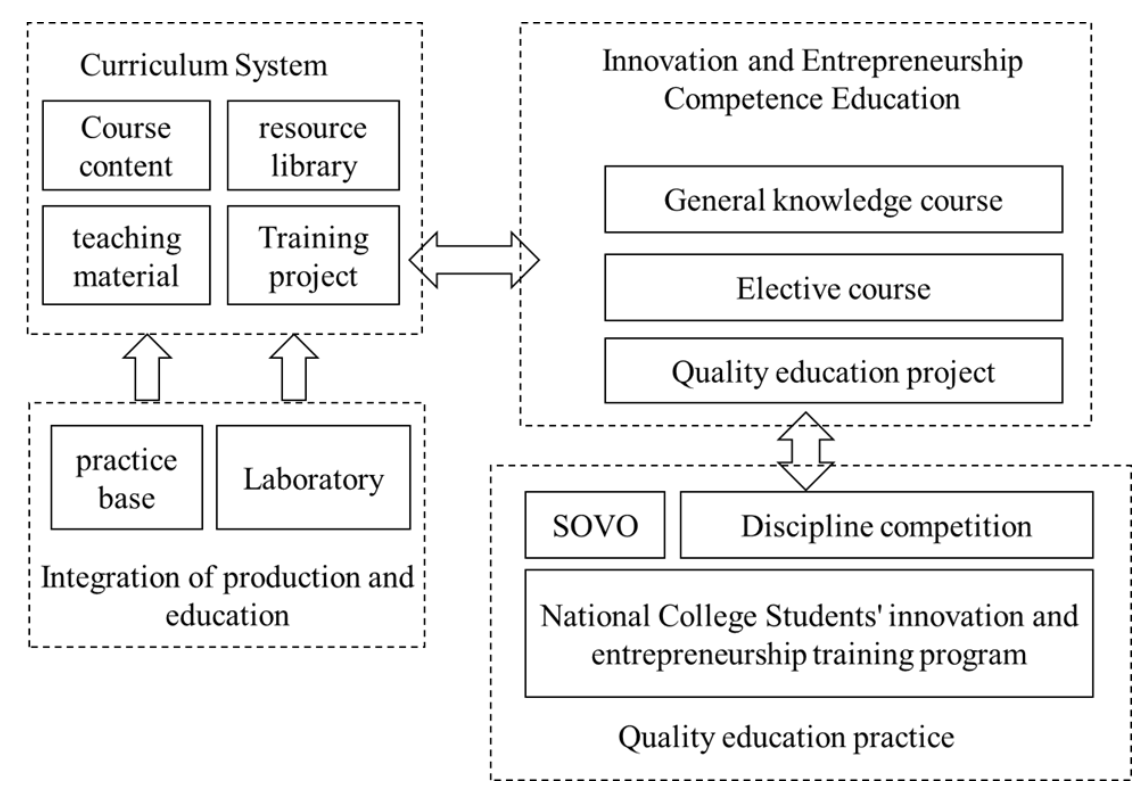

Figure 1. Talent training mode

One side, we have targeted training and guidance of students, simulation of the actual business processes of enterprises, build a soft environment for training, so that students can be integrated into the enterprise as soon as possible after graduation, cleared teaching content according to enterprise demand. On the other hand, the school makes full use of the resources of its partners, and establishes a number of off-campus practice bases, which provides teachers with more opportunities for rotation training and enriches their practical experience. At the same time, the school also provides students with many opportunities for internship in enterprises, opening up a green channel for students to find jobs. In addition, the school also helps students with entrepreneurial enthusiasm, according to the real company's organizational structure to create virtual companies, and actively support students with entrepreneurial ability to start their own businesses[5].

\section{Innovation and entrepreneurship education mode}

Engineering management specialty is a specialty with strong applicability and practicality. The application of knowledge is more important than the possession of knowledge. Over the years, the teaching methods and means of engineering management have been continuously reformed. At present, "case teaching", "scenario simulation", "project into the classroom" and other classroom teaching methods, completely changed the "teacher filled the classroom, students passive acceptance" of the traditional cramming classroom teaching methods[6]. In the teaching reform of engineering management specialty, while applying various teaching methods, under the background of project, the subjective consciousness of students is strengthened in the teaching process, and "interactive teaching" and the summary and communication of students' personal experience are emphasized in the whole process of teaching.

Engineering management majors constantly innovate teaching methods according to the characteristics of different courses. We is heuristic teaching as the guiding ideology. We drive teaching by task, adopt autonomous, interactive, situational, and experiential teaching methods. We combine closely with relevant disciplines and practices to cultivate students'scientific thinking methods, ability to analyze and solve problems. It has stimulated students' interest in learning and achieved better teaching results. The task driven teaching mode is shown in Fig.2. 


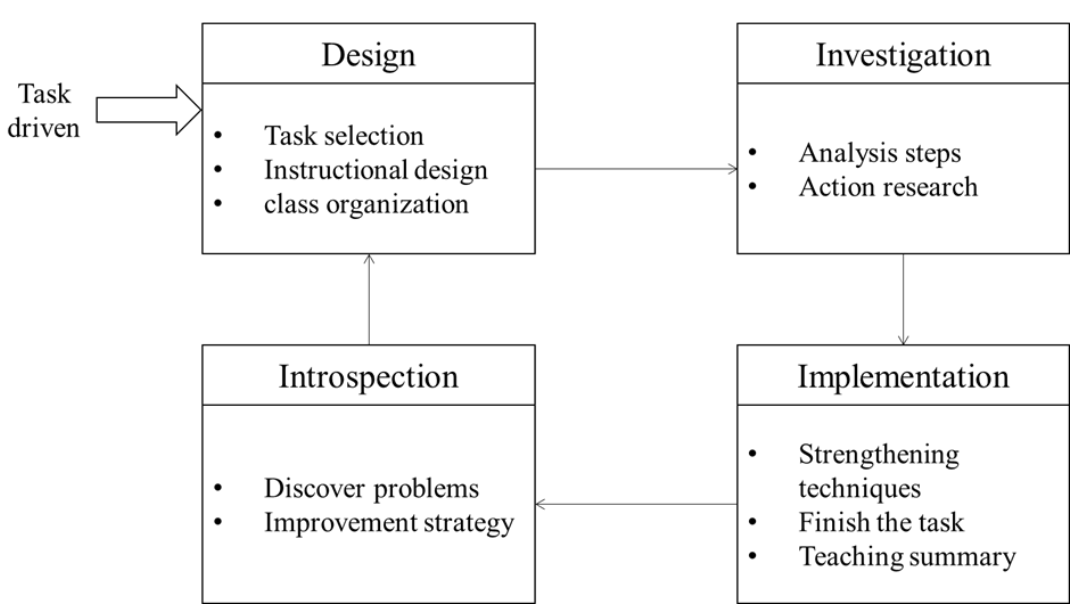

Figure 2. The task driven teaching mode

Under the guidance of task driven teaching mode, many practical teaching methods are derived. Case teaching focuses not only on the local cultural background of the project, but also on the internationalization trend. Combining scenario simulation teaching with laboratory construction to improve the effect of scenario simulation teaching in the course of project time management and the course of project purchasing management. According to the students' ability formation, gradually realize the transition from theory to practice by "mastery of knowledge - formation of basic experimental ability - cultivation of innovative spirit".In addition, new theories, new tools, new methods and new applications will be added to the course to broaden teaching contents[7]. We should improve the standard and content of formative assessment, so that students can change from passive coping to active participation. Practical training, practical projects and graduation design as far as possible to combine with the real topic, to train students'ability to solve practical problems.

\section{Reform of curriculum assessment and evaluation methods}

According to the training objectives and curriculum requirements are different, the course evaluation methods should be used in a variety of ways. For example, closed book examination, open book examination, computer operation, defense, writing papers, etc. According to the characteristics of the course and the criteria and scoring range of the course content, the students'learning quality and learning effect can be evaluated comprehensively[8].

In the process of formative assessment, homework assessment in addition to case analysis form, will be moved to part of classroom practice to stimulate students' teamwork ability and communication skills. The form of examination of small papers is mainly to train students' ability of independent thinking and systematic analysis.

We increase the intensity of our usual achievements, and improve the separation of the original imparting knowledge and examination time. Through flexible and varied exercises and hands-on practice after class, students have a lot of room to play, so that the final examination results closer to the real level of students. The course assessment and evaluation methods are shown in the fig.3. 


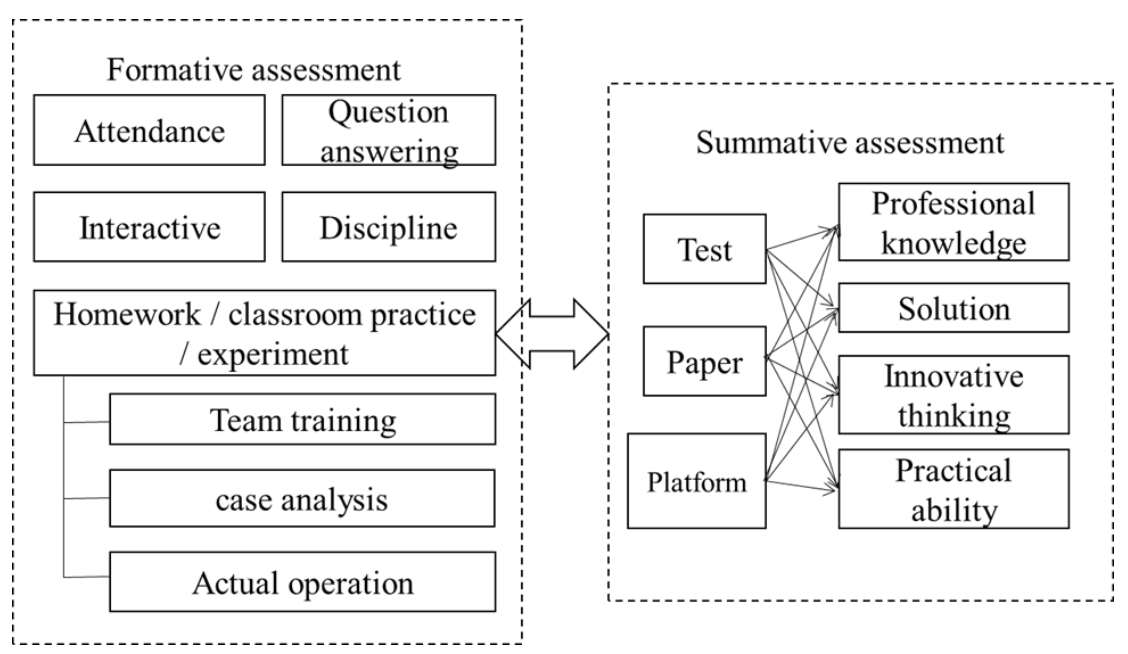

Figure 3. Course assessment and evaluation methods

\section{Summary}

Emerging engineering education needs multidisciplinary integration, through the cross department and Cross University, government, production, learning and research cooperation linkage to cultivate innovative talents with comprehensive ability and quality of the composite. The integration of production education with innovation and entrepreneurship education mode is applied to the construction of Engineering Management Specialty in our university[9][10]. We have established a perfect curriculum system and established a good and extensive school enterprise cooperation relationship. Through the attempt of this innovative talent training mode, we will provide a new and effective way to cultivate diversified and applied talents meeting the needs of the society.

\section{References}

[1] D.H. Zhong. Higher engineering education research, 3(2017) 1-6.

[2] Information on https://baijiahao.baidu.com/s?id=1596689054985416416\&wfr=spider\&for=pc.

[3] S.Z. Wang. Higher engineering education research, 4(2016) 155-159.

[4] S. Huang, M.R.Shang. Higher education journals, 6(2016) 6-7.

[5] J. Wang, X.Q.Xu. Science and technology in Chinese Universities, 7(2016) 55-57.

[6] W.B. Gao. Higher education research in China, 1(2016) 49-50.

[7] J. Hao, A.H. Wu. Higher engineering education research, 2(2016) 7-12.

[8] Information on http://www.ncss.org.cn/tbch/cxcyjyzt/

[9] G.F. Zhao. Innovation and Entrepreneurship Education -- let students walk in the forefront of the times, China Textile Press (2018)

[10]M. Zhang, Y. Zhou. Curriculum education research 14(2016) 